\title{
EFEITO DA UMIDIFICAÇÃO, TRATAMENTO TÉRMICO E DEFORMAÇÃO SOBRE A DECORTICAÇÃO DA CASTANHA DE CAJU 'CCP 76' POR MEIO DE IMPACTO ÚNICO E DIRECIONADO ${ }^{1}$
}

\author{
MAX C. DE ARAÚJO², ANTONIO C. DE O. FERRAZ ${ }^{3}$
}

\begin{abstract}
RESUMO: O sistema mecanizado, de múltiplos impactos, utilizado pela indústria brasileira no beneficiamento da castanha de caju, provoca danos às amêndoas e obtenção de apenas 50 a $60 \%$ de amêndoas inteiras. Para investigar o desempenho da aplicação de deformação limitada, por meio de impacto único e direcionado, um dispositivo especial foi projetado e construído. Determinou-se, inicialmente, a deformação específica correspondente ao melhor desempenho na decorticação. Utilizando-se desse valor, denominado de deformação específica limite, investigou-se o efeito de várias combinações de tempos de umidificação e tratamento térmico, utilizados na preparação da castanha do clone CCP-76, no desempenho da decorticação com impacto único e direcionado. Caracterizaram-se as castanhas pelas dimensões principais e peso, antes a após os tratamentos. $\mathrm{O}$ dispositivo construído mostrou-se eficaz e de fácil operação, sendo o maior índice de 77,55\%, de amêndoas inteiras liberadas, foi obtido com deformação de $19 \%$. Verificou-se que, após a preparação, as castanhas apresentaram perda média de massa de $25,7 \%$, aumento no comprimento, largura e na espessura de 7,03\%; 5,77\% e 7,35\%, respectivamente. Pela metodologia de superfície de resposta, não foram observadas diferenças de desempenho na decorticação.
\end{abstract}

PALAVRAS-CHAVE: Anacardium ocidentale, viscoelasticidade, ruptura.

\section{EFFECT OF MOISTURE CONTENT, THERMAL TREATMENT AND DEFORMATION ON DECORTICATION OF CASHEW NUTS 'CCP 76' BY MEANS OF A GUIDED SINGLE IMPACT}

\begin{abstract}
The mechanized system, of multiple impacts, used by the Brazilian cashew nut industry damages the kernels yielding to only 50 to $60 \%$ of whole kernels. To investigate the performance of shelling cashew nuts using an impact associated with a limited oriented deformation, a special device was designed and constructed. Initially it was found the maximum specific deformation corresponding to the best performance in shelling. With this value, called limit specific deformation, it was investigated the effect of several combinations of humidification and thermal treatment times, commonly used in the preparation of the nut of the clone CCP-76, for shelling, in the performance of a single oriented impact with limited deformation shelling. The cashew nuts were characterized by their dimensions and weight before and after preparation. The impact device showed to be effective and easy to operate. The largest index, of 77,55\%, of liberated whole kernels was obtained to a specific deformation of $19 \%$. After preparation nuts showed average mass loss of $25,7 \%$, increase in length, width and thickness of $7,03 \%, 5,77 \%$ e $7,35 \%$, respectively. For the answer surface methodology, no differences in shelling performance was observed among treatments suggesting.
\end{abstract}

KEYWORDS: Anacardium ocidentale, viscoelasticity, rupture.

\footnotetext{
${ }^{1}$ Extraído da tese de doutorado do primeiro autor.

${ }^{2}$ Prof. Doutor, Câmpus Amílcar Ferreira Sobral, Universidade Federal do Piauí, max@ufpi.br

${ }^{3}$ Prof. Livre-Docente, Faculdade de Engenharia Agrícola, Universidade Estadual de Campinas, UNICAMP, carlos@agr.unicamp.br

Recebido pelo Conselho Editorial em: 13-2-2006

Aprovado pelo Conselho Editorial em: 17-8-2006
} 


\section{INTRODUÇÃO}

A castanha de caju é o verdadeiro fruto do cajueiro (Anacardium ocidentale L), explorado comercialmente nos continentes Asiático, Africano e Sul-Americano. Destacam-se, como principais exportadores da amêndoa de castanha de caju (ACC), a Índia, o Vietnã e o Brasil. As castanhas apresentam tamanho variável, cor cinza-amarronzada, epicarpo liso, mesocarpo alveolado - contendo um líquido escuro, cáustico e inflamável, denominado líquido da casca da castanha (LCC), que representa $22 \%$ do peso da castanha - endocarpo, camada mais interna que oferece maior resistência à ruptura da amêndoa.

A amêndoa representa, em média, 28,3\% do peso total do fruto. De acordo com OHLER (1979), citado por OLOSO \& CLARKE (1993), a decorticação com liberação da amêndoa apresenta grandes desafios, tais como: irregularidade no formato da castanha, fragilidade da amêndoa e a sua facilidade de contaminação pelo LCC. Além desses fatores, a variabilidade nas dimensões da castanha e a pouca folga entre a amêndoa e o endocarpo dificultam a ruptura da casca quando se quer preservar a integridade da amêndoa.

O conhecimento das propriedades mecânicas dos materiais biológicos contribui com parâmetros para projetar equipamentos e propor ações mais adequadas para melhorar a qualidade do beneficiamento de produtos agrícolas (ARAÚJO, 1999; LEITÃO, 1983).

Uma forma de diminuir o número de danos às amêndoas na decorticação da castanha de caju consiste na aplicação de uma carga, em curto espaço de tempo, provocando aumento de tensão e, conseqüentemente, a sua ruptura. Quanto maior a deformação imposta, maiores são os riscos de danos à amêndoa. $\mathrm{O}$ componente viscoso, pela sua dependência temporal, assume papel importante na redução da deformação necessária à ruptura, uma vez que o crescimento das tensões internas está associado à taxa de deformação. Limitar a deformação para o rompimento da casca proporcionará menores danos à amêndoa. Esse valor de deformação limitada, como parcela da dimensão original pertinente, foi denominado deformação específica limite.

Este trabalho teve por objetivos determinar a deformação específica limite de uma classe da castanha de caju do clone 'CCP 76', na direção de sua largura, por meio de impacto único e direcionado, ao longo da largura da castanha, e investigar o desempenho do impacto na abertura das castanhas para várias combinações de tempo de umidificação e residência no LCC a $210{ }^{\circ} \mathrm{C}$.

\section{MATERIAL E MÉTODOS}

\section{Determinação da deformação específica limite para castanhas ' $\mathrm{CCP}$ 76' com largura entre 30,4 e 25,5 mm}

Utilizaram-se castanhas de caju in natura fornecidas pela Embrapa - Centro Nacional de Pesquisa da Agroindústria Tropical, Fortaleza - CE, que foram separadas em quatro lotes com 25 unidades e pesadas individualmente em balança com 0,1g de precisão. Para medir o comprimento, largura e espessura de cada castanha (Figura 1), utilizou-se paquímetro digital (DIGIMESS) com resolução centesimal de milímetro.

As castanhas foram umidificadas por imersão em água por de 2 horas e, drenada a água, submetidas a período de repouso de 86 horas em recipiente fechado. Após a umidificação, procedeu-se o tratamento térmico por meio de "banho" em LCC a $210{ }^{\circ} \mathrm{C}$, por $150 \mathrm{~s}$, seguido de período de repouso de 2 horas, para resfriamento. Seguiram-se a retirada do excesso de LCC superficial com papel absorvente, medidas das principais dimensões, pesagem e aplicação do impacto direcionado com deformação limitada, utilizando-se do dispositivo de impacto. Avaliou-se o desempenho do impacto para as deformações específicas limites, isto é, máximas deformações permitidas na direção da largura de $15 ; 17 ; 19$ e $21 \%$. 


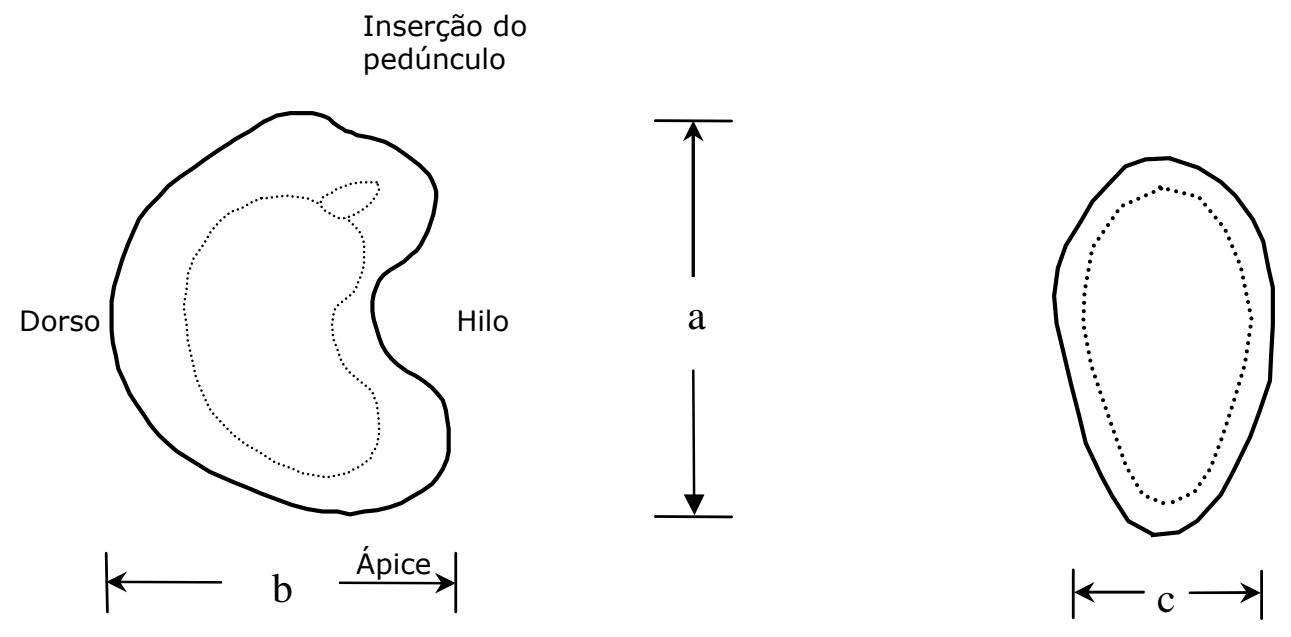

FIGURA 1. Dimensões características da castanha de caju. Comprimento (a), largura (b) e espessura (c).

O teor de água da castanha de caju foi determinado após o tratamento térmico, utilizando-se da metodologia proposta pela ASAE S410.1 (1992), porém com temperatura da estufa de ar forçado a $65^{\circ} \mathrm{C} \pm 3{ }^{\circ} \mathrm{C}$ para facilitar a estabilização do peso, até atingir peso constante. Como a metodologia requer os percentuais de casca e amêndoas em relação à massa total da castanha de caju 'CCP 76', considerou-se para a casca o valor de $71,23 \%$ e para a amêndoa $28,77 \%$, segundo determinações realizada por ARAÚJO et al. (2003).

\section{Dispositivo de impacto com deformação limitada (DIDL)}

O dispositivo de impacto, mostrado esquematicamente na Figura 2, projetado e construído para imprimir golpe com deformação limitada, é composto por conduto vertical que permite deslizamento de martelo plano de aço 1020 . O martelo (722,5 g) pode ser elevado, manualmente, por um sistema de cabo e polias, sendo liberado para movimento em queda livre, atingindo a base com velocidade de $4,18 \mathrm{~m} \mathrm{~s}^{-1}$.

O conduto vertical está afixado na estrutura do dispositivo de forma a não permitir movimentos relativos. O conjunto é rígido, e suas deformações, no momento do impacto, são consideradas pequenas se comparadas às da castanha. Na extremidade inferior do conduto vertical, localiza-se uma base plana com orifício central onde está inserida uma plataforma de altura regulável, denominada de base ajustável. Cada castanha é posicionada sobre a base ajustável, na direção da largura e com dorso voltado para cima, regulando-se a altura da base ajustável de modo a permitir que somente parcela da largura ultrapasse o nível da superfície superior da base plana. Essa parcela exposta representa a deformação máxima permitida no momento do impacto com o martelo plano, sendo denominada também de deformação específica limite quando a deformação máxima é expressa em percentagem da largura da castanha. A superfície da base ajustável foi revestida com lixa $\mathrm{n}^{\mathrm{o}} 240$ para evitar o deslizamento da castanha. 


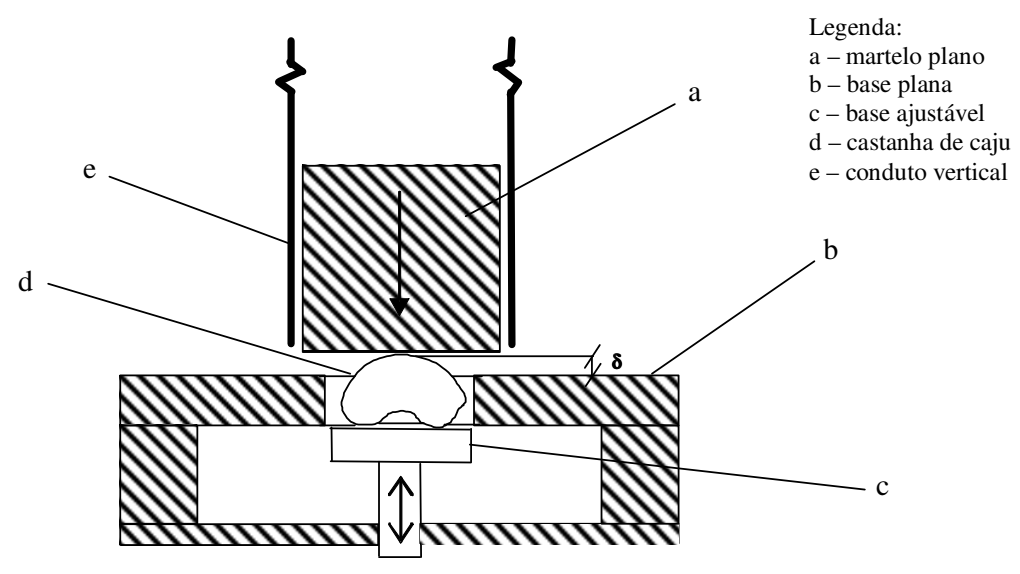

FIGURA 2. Representação esquemática do dispositivo de impacto mostrando a aplicação direcionada da força e deformação $(\delta)$.

\section{Critério de avaliação do efeito do impacto}

Após o golpe, o martelo plano é levantado e a castanha retirada do dispositivo para avaliação do efeito do impacto, segundo o número de ocorrências das seguintes classes: castanhas com ruptura total da casca e amêndoa inteira liberada (RtAi); castanhas com ruptura parcial da casca e amêndoa protegida (RpAp), porém apresentando potencial de completar a ruptura por meio de solicitação mecânica semelhante; castanha com ruptura parcial da casca e amêndoa exposta (RpAe), mas sem potencial de completar a ruptura por meio de um impacto semelhante, e castanha com ruptura total da casca e amêndoa danificada (RtAd). Buscou-se a deformação específica que resultasse no maior número de castanhas com ruptura total da casca e amêndoa inteira liberada (RtAi).

\section{Efeito de diversas combinações de tempos de umidificação e tratamento térmico na abertura das castanhas}

Utilizaram-se castanhas da mesma procedência e classe, adotando-se o mesmo procedimento descrito anteriormente para a caracterização das dimensões e peso das castanhas. Para cada ensaio, foram utilizadas 50 castanhas, num total de 550 castanhas. Cada lote de 50 castanhas foi imerso em água por um período de 2 horas, seguidos por períodos de repouso de 72; 79; $86 ; 93$ e 100 horas em recipiente fechado. Em seguida, foram mergulhadas em LCC, à semelhança de uma fritura em óleo, a $210^{\circ} \mathrm{C}$, por $120 ; 135 ; 150 ; 165$ e $180 \mathrm{~s}$.

O LCC foi drenado, seguido de retirada do LCC superficial restante com papel absorvente e período de repouso de 2 horas em condições ambientes. Medidas das principais dimensões e peso foram feitas após o banho para identificar as variações. Utilizou-se novamente do DIDL, ajustando-se para cada castanha o valor da deformação específica limite encontrado no experimento anterior e o mesmo critério de avaliação de desempenho.

\section{Planejamento experimental}

Aplicou-se a metodologia de superfície de resposta (BARROS NETO et al., 2002) para analisar o efeito combinado do tempo de umidificação e do tempo de residência no LCC. $\mathrm{O}$ delineamento experimental escolhido foi o fatorial $2^{2}$, com três pontos na região central e quatro pontos axiais, com nove tratamentos, totalizando 11 pontos experimentais. A composição dos tratamentos é apresentada na Tabela 1, sendo a ordem dos fatores aleatória, e o ponto central teve três repetições 5; 6 e 7, de acordo com a metodologia.

Esse tipo de planejamento estatístico gera modelo quadrático, no qual o valor das variáveis dependentes Y (ruptura total e amêndoa inteira; ruptura parcial e amêndoa protegida; ruptura parcial e amêndoa exposta, e ruptura total e amêndoa danificada) é função das variáveis 
independentes (tempo de umidificação e tempo de residência no LLC, a $210{ }^{\circ} \mathrm{C}$ ), conforme descreve a eq.(1).

$$
\mathrm{Y}=\varphi(\mathrm{Tu}, \mathrm{Tr})=\beta_{0}+\beta_{1} \mathrm{Tu}+\beta_{2} \operatorname{Tr}+\beta_{11} \mathrm{Tu}^{2}+\beta_{22} \operatorname{Tr}^{2}+\beta_{12} \operatorname{Tu} \mathrm{Tr}
$$

TABELA 1. Variáveis codificadas e decodificadas do planejamento experimental para a avaliação do efeito combinado de umidificação e tratamento térmico submetido à castanha de caju 'CCP 76' no impacto direcionado.

\begin{tabular}{crrrc}
\hline \multirow{2}{*}{ Ensaios } & \multicolumn{2}{c}{ Codificado } & \multicolumn{2}{c}{ Decodificado } \\
\cline { 2 - 5 } & $\mathrm{Tu}$ & $\mathrm{Tr}$ & $\mathrm{Tu}(\mathrm{h})$ & $\operatorname{Tr}(\mathrm{s})$ \\
\hline 1 & -1 & -1 & 79 & 135 \\
2 & 1 & -1 & 93 & 135 \\
3 & -1 & 1 & 79 & 165 \\
4 & 1 & 1 & 93 & 165 \\
5 & 0 & 0 & 86 & 150 \\
6 & 0 & 0 & 86 & 150 \\
7 & 0 & 0 & 86 & 150 \\
8 & -2 & 0 & 72 & 150 \\
9 & 2 & 0 & 100 & 150 \\
10 & 0 & -2 & 86 & 120 \\
11 & 0 & 2 & 86 & 180 \\
\hline
\end{tabular}

Tu - tempo de umidificação e $\mathrm{Tr}$ - tempo de residência no LLC, a $210^{\circ} \mathrm{C}$.

Os pontos centrais servem para estimar o erro experimental e determinar a precisão da equação polinomial. Os pontos axiais $( \pm \alpha)$ são utilizados para a ampliação do modelo linear, tornando-o modelo quadrático. Os modelos de regressão foram gerados pelo software STATISTICA 6.0, sendo considerado preditivo o modelo com regressão significativa a 95\% de confiança, falta de ajuste não-significativa ao mesmo nível de confiança e alto valor de $\mathrm{R}^{2}$ (BARROS NETO et al., 2002).

Como resultado, o efeito estimado indica o quanto cada fator influi nas respostas estudadas. Quanto maior é o seu valor, maior é a influência, e efeito de sinal positivo indica que, ao passar de um valor mínimo a um valor máximo da variável, a resposta aumenta. Contrariamente, efeito de sinal negativo indica que, ao passar de um valor mínimo para o valor máximo, a resposta diminui. O planejamento estatístico indicará uma região de máximo ou de mínimo na resposta, em função do tempo de umidificação e de residência no LCC, ou seja, a região na qual as características mecânicas do material apontem para o que se deseja. A superfície de resposta pode proporcionar economia de tempo ou redução de custo no processo de beneficiamento da castanha de caju para a indústria. Resultados iguais na mesma região poderão sugerir ponto de ótimo, visando a minimizar os custos e o tempo gasto no processo de beneficiamento.

\section{RESULTADOS E DISCUSSÃO}

\section{Resultados do ensaio de impacto para a determinação da deformação específica limite Dimensões e peso das castanhas ensaiadas}

As castanhas apresentaram dimensões médias, antes do tratamento térmico de 32,93 mm, com coeficiente de variação (C.V.) de $3 \%$ para o comprimento, $26,80 \mathrm{~mm}(\mathrm{C} . \mathrm{V} .=3 \%$ ) para a largura e 20,05 mm (C.V.=4\%) para a espessura. O peso apresentou valor médio de 8,44 g $(\mathrm{C} . \mathrm{V} .=$ 9\%). Após o tratamento térmico, apresentaram dimensões médias de 35,56 mm (C.V.=3\%) para o comprimento, $28,98 \mathrm{~mm}(\mathrm{C} . \mathrm{V} .=3 \%)$ para a largura e $21,71 \mathrm{~mm}(\mathrm{C} . \mathrm{V} .=4 \%)$ para a espessura. $\mathrm{O}$ peso apresentou valor médio de 6,60 g (C.V.=8\%). Observou-se, em média, aumento de 7,98\% para o comprimento, $8,13 \%$ para a largura e $8,28 \%$ para a espessura, verificando-se redução média na massa de $21,8 \%$. O teor de água médio encontrado para a castanha foi de $5,83 \%$ b.s. (C.V.= 19\%). 


\section{Ensaios para determinação da deformação específica limite}

O dispositivo construído para determinar a deformação específica limite mostrou-se eficiente na condução do ensaio, não apresentando dificuldades operacionais. No entanto, recomendam-se alguns cuidados, tais como: ajuste de altura da base móvel para a aplicação da deformação específica, retirada e limpeza periódica da base móvel, lançamento do martelo plano a uma mesma altura e levantamento do martelo logo após o impacto. As fotos (Figura 5) obtidas após o impacto ilustram as classes utilizadas para a avaliação do efeito do impacto.
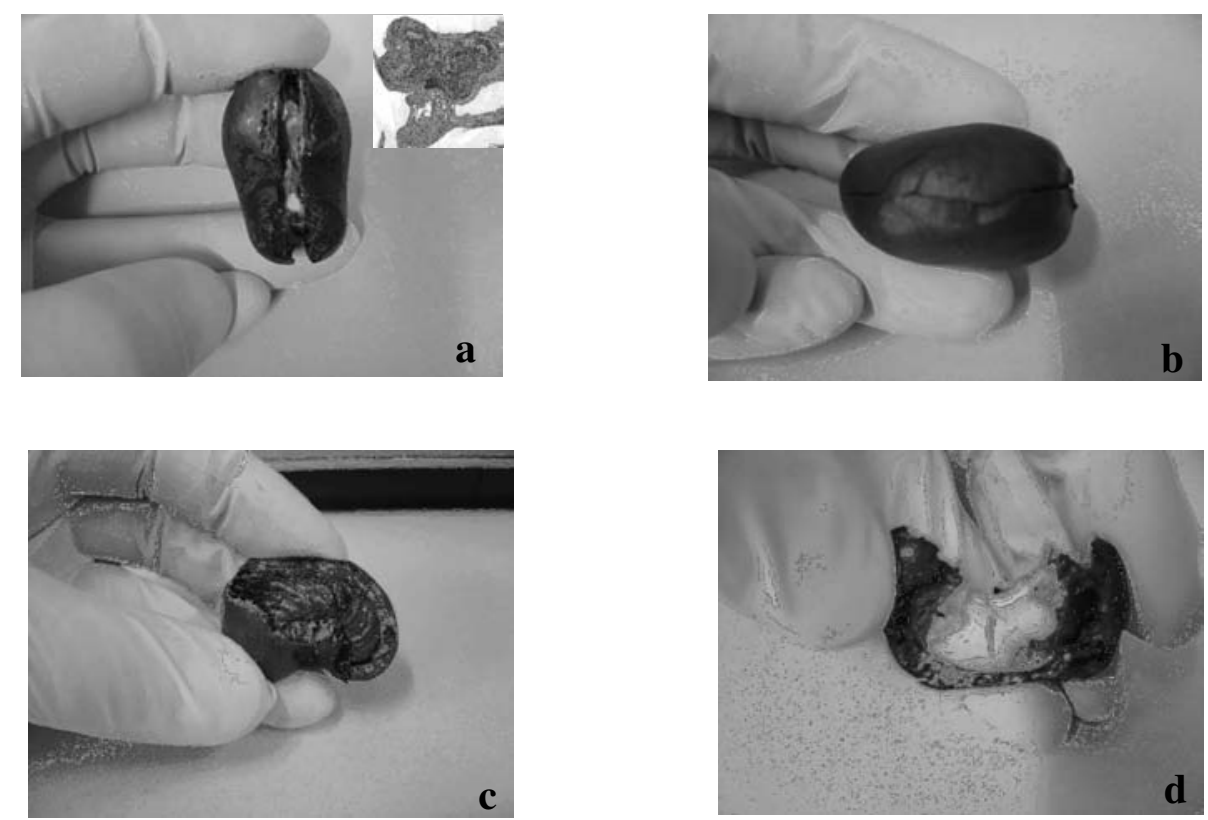

FIGURA 5. Castanhas submetidas ao ensaio de impacto, mostrando cada classe: a - ruptura total e amêndoa inteira; b - ruptura parcial e amêndoa protegida; c- ruptura parcial e amêndoa exposta; d - ruptura total e amêndoa danificada.

Os resultados de desempenho do impacto (Tabela 2) mostram que com a deformação específica de $19 \%$, obteve-se maior número de castanhas com ruptura total da casca e liberação de amêndoa inteira e o mínimo com a ruptura parcial da casca e amêndoa protegida, ruptura parcial da casca e amêndoa exposta, como também para a ruptura total da casca e amêndoa danificada. Com $21 \%$ de deformação, verifica-se percentual de 40,9\% de ruptura total da casca com amêndoa danificada, condição indesejável, evidenciando o efeito da deformação excessiva aplicada. O maior percentual de ruptura parcial da casca e da amêndoa protegida foi observado na deformação específica de $15 \%$, indicando o efeito de deformação insuficiente.

TABELA 2. Desempenho do impacto único e direcionado, em castanhas de caju, em percentagem de castanhas ensaiadas, a várias deformações específicas.

\begin{tabular}{lrrrr}
\hline \multirow{2}{*}{ Classes } & \multicolumn{3}{c}{ Deformações Específicas } \\
\cline { 2 - 5 } & $15 \%$ & $17 \%$ & $19 \%$ & \multicolumn{1}{c}{$21 \%$} \\
\hline Ruptura total e amêndoa inteira $(\%)^{1}$ & 36,00 & 60,87 & 75,00 & 50,00 \\
Ruptura parcial e amêndoa protegida $(\%)^{2}$ & 40,00 & 30,43 & 20,83 & 9,10 \\
Ruptura parcial e amêndoa exposta $(\%)^{3}$ & 16,00 & 4,35 & 0,00 & 0,00 \\
Ruptura total e amêndoa danificada $(\%)^{4}$ & 8,00 & 4,35 & 4,17 & 40,90 \\
\hline
\end{tabular}

${ }^{1}$ Castanha com ruptura total da casca e amêndoa inteira; ${ }^{2}$ Castanha com ruptura parcial da casca e amêndoa protegida (tendo potencial de abertura total por meio de solicitação mecânica adicional); ${ }^{3}$ Castanha com ruptura parcial da casca e amêndoa exposta ( sem possibilidade de novo impacto na mesma direção); ${ }^{4}$ Castanha com ruptura total da casca e da amêndoa danificada. 
Para a confirmação desse resultado, repetiu-se o experimento utilizando lote de 50 castanhas com mesma faixa de tamanho, procedimentos de umidificação e tratamento térmico, porém para a deformação específica de 19\%. O resultado obtido (Tabela 3), de 77,55\% de ruptura total da casca com amêndoa inteira, confirma o anterior e aponta para o potencial desse procedimento na obtenção de grande número de amêndoas inteiras com um único impacto e deformação limitada ao longo da largura da castanha. Observa-se que o percentual de castanhas com ruptura total da casca e amêndoa danificada foi de $18,37 \%$, sendo $14,20 \%$ maior que o resultado correspondente anterior, devido à variabilidade do material biológico. No caso de castanhas com ruptura parcial da casca e amêndoa protegida, obteve-se redução de $16,75 \%$.

TABELA 3. Desempenho do impacto único e direcionado na abertura de castanhas de caju, expresso em percentagem, com deformação específica de 19\%, para 50 castanhas.

\begin{tabular}{lc}
\hline \multicolumn{1}{c}{ Classes } & Deformação Específica de 19\% \\
\hline Ruptura total e amêndoa inteira (\%) & 77,55 \\
Ruptura parcial e amêndoa protegida $(\%)^{1}$ & 4,08 \\
Ruptura parcial e amêndoa exposta $(\%)^{3}$ & 0,00 \\
Ruptura total e amêndoa danificada (\%) & 18,37 \\
\hline${ }^{1}$ Castanha com ruptura total da casca e amêndoa inteira; ${ }^{2}$ Castanha com ruptura parcial da casca e amêndoa protegida \\
(tendo potencial de abertura total por meio de solicitação mecânica adicional); ${ }^{3}$ Castanha com ruptura parcial da \\
casca e amêndoa exposta (sem possibilidade de novo impacto na mesma direção); ${ }^{4}$ Castanha com ruptura total da \\
casca e da amêndoa danificada.
\end{tabular}

\section{Efeito de diversas combinações de tempos de umidificação e tratamento térmico na abertura das castanhas}

\section{Dimensões médias e peso das castanhas de caju}

As castanhas dos 11 tratamentos investigados apresentaram dimensões médias, antes do tratamento térmico, de $32,43 \mathrm{~mm}$, com coeficiente de variação $(\mathrm{C} . \mathrm{V} .=1 \%$ ) para o comprimento, de $26,49 \mathrm{~mm}(\mathrm{C} . \mathrm{V} .=1 \%)$ para a largura, de $20,26 \mathrm{~mm}$ para a espessura $(\mathrm{C} . \mathrm{V} .=1 \%)$ e $8,56 \mathrm{~g}(\mathrm{C} . \mathrm{V} .=$ $4 \%$ ) para o peso. Após o tratamento térmico, as castanhas apresentaram dimensões médias de 34,71 $\mathrm{mm}(\mathrm{C} . \mathrm{V} .=7 \%)$ para o comprimento, de $28,02 \mathrm{~mm}(\mathrm{C} . \mathrm{V} .=7 \%)$ para a largura, de $21,75 \mathrm{~mm}$ para a espessura $(\mathrm{C} . \mathrm{V} .=11 \%)$ e $6,36 \mathrm{~g}(\mathrm{C} . \mathrm{V} .=19 \%)$ para o peso. Observou-se, em média, acréscimo de $7,03 \%$ para o comprimento, 5,77\% para a largura e 7,35\% para a espessura, verificando-se redução média na massa de $25,7 \%$. A umidade em base seca variou de 5,15\% a 3,29\%.

\section{Ensaios de impacto com aplicação da deformação específica limite de 19\%}

Mostra-se, na Figura 6, o resultado da avaliação de desempenho na ruptura das castanhas por meio do ensaio de impacto direcionado para os diversos tratamentos realizados. O melhor desempenho de ruptura total da casca com amêndoa inteira foi do ensaio 1, com 87,5\%, correspondendo ao menor valor de ruptura parcial da casca e amêndoa protegida, com 2,08\%, e de ruptura total da casca e amêndoa danificada, $4,17 \%$. O ensaio 3 apresentou o pior resultado de ruptura total da casca com amêndoa inteira 72,34\%. O maior índice de amêndoas danificadas, 20\%, foi observado no ensaio 9. O efeito combinado do tempo de umidificação e de residência no LCC altera as características físicas da castanha, apontando para diferenças de desempenho nos diversos tratamentos estudados. 


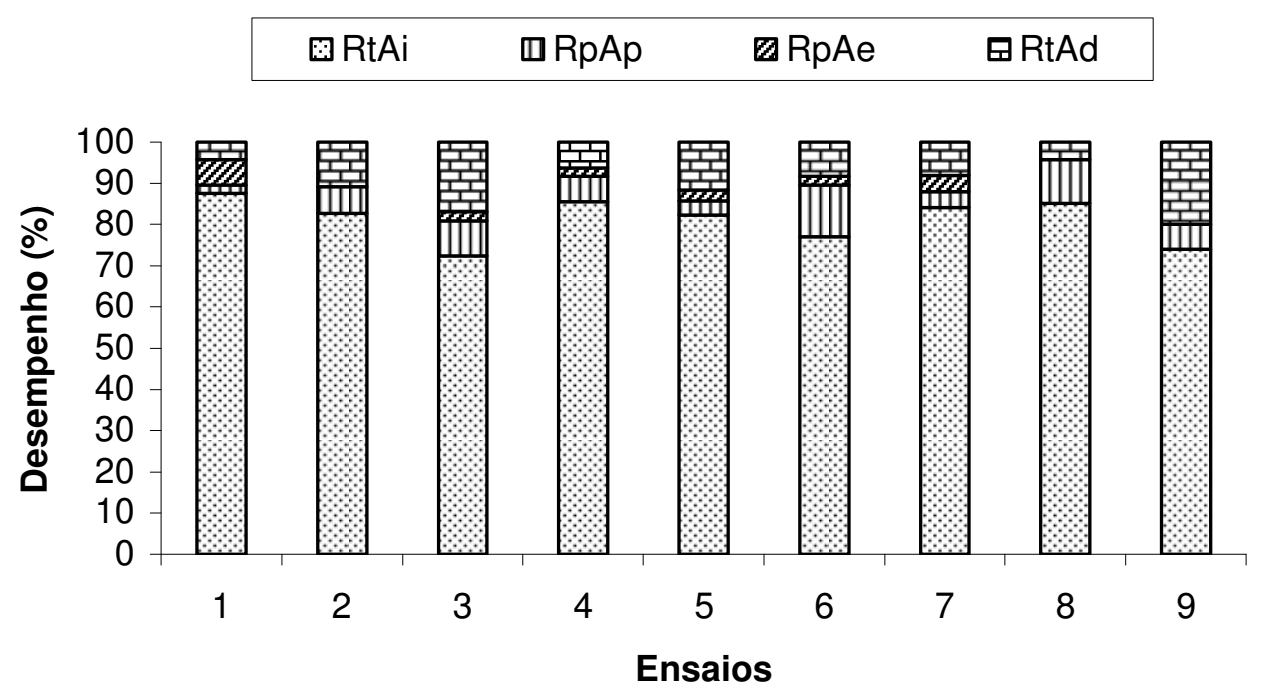

FIGURA 6. Desempenho da ruptura das castanhas por meio do impacto único e direcionado na ruptura total da casca com amêndoa inteira (RtAi), ruptura parcial da casca com amêndoa protegida (RpAp), ruptura parcial da casca com amêndoa exposta (RpAe) e ruptura total da casca com amêndoa danificada (RtAd), expresso em percentagem, para a deformação específica de $19 \%$.

\section{Comparação do desempenho entre os diversos tratamentos}

\section{Ruptura total da casca com amêndoa inteira}

Os resultados da análise estatística aplicada aos dados experimentais de ruptura total da casca e amêndoa inteira, no ensaio de impacto da castanha de caju, são apresentados na Tabela 4. Observa-se que os efeitos estimados foram não-significativos $(\mathrm{p} \leq 0,05)$.

TABELA 4. Efeito estimado, erro puro e grau de significância para ruptura total da casca e amêndoa inteira no ensaio de impacto da castanha de caju.

\begin{tabular}{lccc}
\hline \multicolumn{1}{c}{ Fonte de Variação } & Efeito & Erro Puro & $\mathrm{p}$ \\
\hline Média global & 82,8558 & 3,3026 & $0,0016^{*}$ \\
Tempo de umidificação (L) & 3,6717 & 3,7169 & $0,4274 \mathrm{~ns}$ \\
Tempo de umidificação (Q) & $-0,9270$ & 2,9308 & $0,7817 \mathrm{~ns}$ \\
Tempo de residência (L) & $-4,0583$ & 3,7169 & $0,3889 \mathrm{~ns}$ \\
Tempo de residência (Q) & $-2,6970$ & 2,9308 & $0,4546 \mathrm{~ns}$ \\
Interação (L) & 8,9850 & 6,4379 & $0,2976 \mathrm{~ns}$ \\
\hline
\end{tabular}

* significativo a 5\% de probabilidade; ns - não-significativo

O tempo de umidificação e a interação linear tiveram efeitos positivos, indicando que a resposta ruptura total da casca com amêndoa inteira deve ser maior quando se aumenta o tempo de umidificação ou a interação dos dois fatores estudados. O tempo de residência linear tem efeito negativo, sugerindo que a resposta diminui quando a castanha passa mais tempo no LCC, a $210{ }^{\circ} \mathrm{C}$. Quando se compara o tempo de umidificação e a interação linear, observa-se que o maior efeito é para a interação, pois é a que tem maior valor. Como não se observaram diferenças estatísticas a 95\% de confiança para os fatores estudados, apresenta-se, na Figura 7, a tendência da superfície de resposta e curva de contorno para ruptura total da casca e amêndoa inteira em função do tempo de umidificação e tempo de residência no $\mathrm{LCC}$, a $210^{\circ} \mathrm{C}$. Verifica-se que a região de máximo está fora da faixa estudada, sendo o ensaio 1 que mais se aproxima dessa região. 

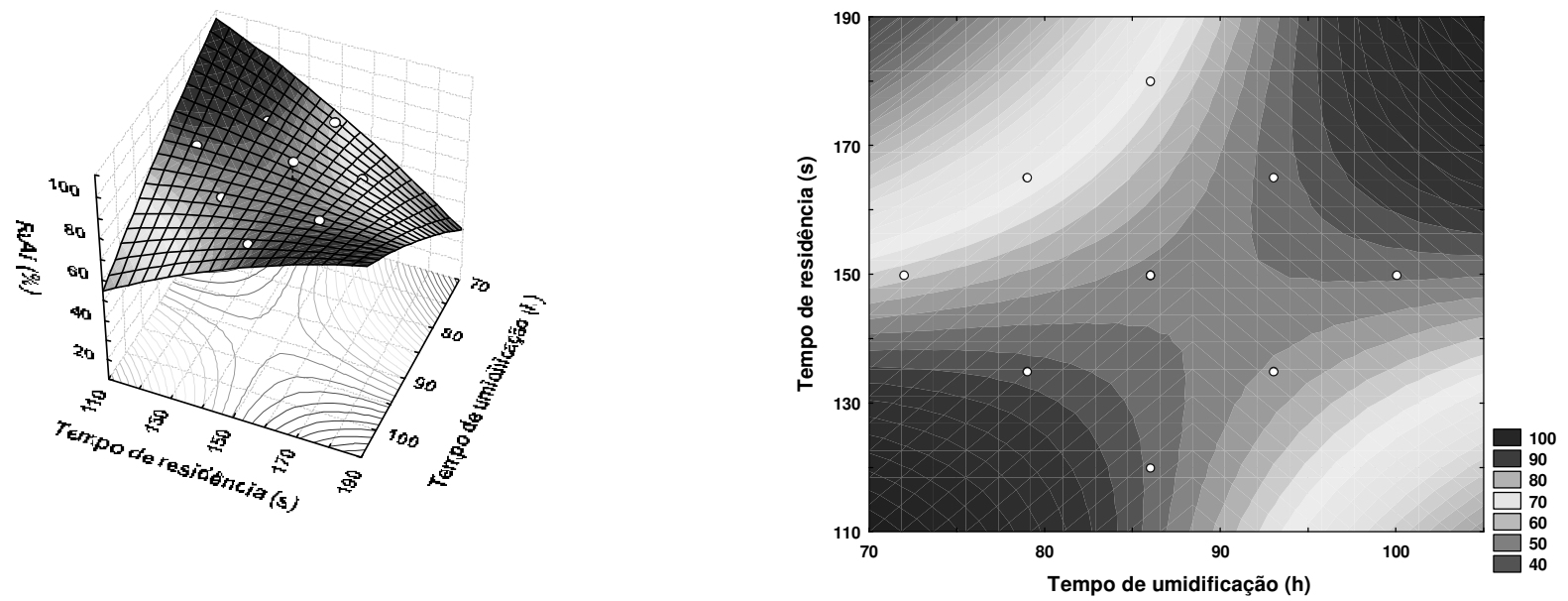

FIGURA 7. Tendência da superfície de resposta e curva de contorno para a ruptura total da casca e amêndoa inteira em função do tempo de umidificação e do tempo de residência no ensaio de impacto.

Para as respostas de ruptura parcial da casca com amêndoa protegida, ruptura parcial da casca com amêndoa exposta e ruptura total da casca com amêndoa danificada, obtiveram-se resultados semelhantes, não apresentando diferenças estatísticas a 95\% de confiança, gerando tendência da superfície de resposta.

Observa-se que o efeito combinado do tempo de umidificação e de residência no LCC, a $210^{\circ} \mathrm{C}$, é que oferece maior influência nas respostas estudadas; no entanto, a faixa de variação dos fatores escolhida, com base nos dados da indústria de beneficiamento, não apresentou diferenças estatisticamente significativas, apontando para a necessidade de ampliação da faixa de estudo.

\section{CONCLUSÕES}

O dispositivo proposto para a determinação da deformação específica limite mostrou-se eficaz e pode ser utilizado nas comparações de desempenho de mecanismos de decorticação. Os resultados obtidos com os diversos lotes de castanhas ensaiados evidenciam potencial de obtenção de grande número de amêndoas inteiras com a aplicação de um único impacto, com deformação limitada, ao longo da largura da castanha.

Para as combinações de tempos de umidificação e residência em LCC, a $210{ }^{\circ} \mathrm{C}$, não foram observadas diferenças significativas de desempenho da decorticação, sugerindo que, nessa grande faixa de variação das condições de preparação, devam ser investigadas as condições mais econômicas.

\section{AGRADECIMENTOS}

À Embrapa Agroindústria Tropical, Fortaleza - CE, pelo apoio e castanhas cedidas, e ao Laboratório de Propriedades Mecânicas dos Materiais Biológicos, da Faculdade de Engenharia Agrícola, UNICAMP, Campinas - SP, pelo apoio técnico.

\section{REFERÊNCIAS}

ARAUJO, F.V.M.; FERRAZ, A.C.O.; ARAÚJO, M.C.; AUGUSTO, P.E.D. Comparação entre dois métodos de determinação de umidade de castanha de caju. SIMPÓSIO LATINO-

AMERICANO DE CIÊNCIA DE ALIMENTOS, 5., 2006, Campinas. Anais... Campinas:

UNICAMP, 2003. 1 CD-ROM. 
ARAÚJO, M.C. Desenvolvimento e avaliação de uma máquina descascadora de amendoim. $81 \mathrm{f}$. Dissertação (Mestrado em Engenharia Mecânica) - Centro de Ciências e Tecnologia, Universidade Federal da Paraíba, Campina Grande, 1999.

ASAE S410.1. Moisture Measurement - Peanut: In: ASAE Standards 1994. St. Joseph, 1994. p.477-8.

BARROS NETO, B.; SCARMINIO, I.S.; BRUNS, R.E. Como fazer experimentos: pesquisa e desenvolvimento na ciência e na indústria. Campinas: Editora da UNICAMP, 2002. 401 p.

LEITÃO, A.M. Algumas propriedades físicas e mecânicas da pimenta-do-reino preta, variedade kaluvally. 1983. 109 f. Dissertação (Mestrado em Engenharia de Alimento e Agrícola) - Faculdade de Engenharia de Alimentos e Agrícola, Universidade Estadual de Campinas, Campinas, 1983.

OLOSO, A.O.; CLARKE, B. Some aspects of strength properties of Cashew nuts. Journal of Agricultural Engineering Research, London, v.55, n.1, p.27-43, 1993. 